\title{
Properties of screen printed electrocardiography smartware electrodes investigated in an electro-chemical cell
}

\author{
Linda Rattfält ${ }^{*}$, Fredrik Björefors ${ }^{2}$, David Nilsson ${ }^{3}$, Xin Wang $^{3}$, Petronella Norberg ${ }^{3}$ and Per Ask ${ }^{1}$
}

* Correspondence:
Linda.rattfalt@liu.se
'Department of Biomedical
Engineering, Linköping University,
SE-581 83, Linköping, Sweden
Full list of author information is
available at the end of the article

* Correspondence:

Cindarattfalt@liu.se

Engineering, Linköping University,

Full list of author information is

\section{Biomed Central}

\begin{abstract}
Background: ECG (Electrocardiogram) measurements in home health care demands new sensor solutions. In this study, six different configurations of screen printed conductive ink electrodes have been evaluated with respect to electrode potential variations and electrode impedance.

Methods: The electrode surfaces consisted of a $\mathrm{Ag} / \mathrm{AgCl}$-based ink with a conduction line of carbon or Ag-based ink underneath. On top, a lacquer layer was used to define the electrode area and to cover the conduction lines. Measurements were performed under well-defined electro-chemical conditions in a physiologic saline solution.

Results: The results showed that all printed electrodes were stable and have a very small potential drift (less than $3 \mathrm{mV} / 30 \mathrm{~min}$ ). The contribution to the total impedance was $2 \%$ of the set maximal allowed impedance (maximally $1 \mathrm{k} \Omega$ at $50 \mathrm{~Hz}$ ), assuming common values of input impedance and common mode rejection ratio of a regular amplifier.
\end{abstract}

Conclusion: Our conclusions are that the tested electrodes show satisfying properties to be used as elements in a skin electrode design that could be suitable for further investigations by applying the electrodes on the skin.

Keywords: Screen printed electrodes, ECG, Electrode impedance, Electrode potential, Smartware electrodes

\section{Background}

As a consequence of the increasing number of elderly with cardiovascular diseases there is a healthcare driven need to develop new solutions for home health care. The electrocardiogram (ECG) is an important diagnostic and monitoring modality in point of care systems. This requires a robust wearable ECG acquisition system and smartware has in this context been introduced as a possible solution [1]. Textile electrodes for ECG measurements incorporated in clothes or similar setups have been tested and evaluated [2-5] over the last decade. The textile electrodes, however, often have a complex structure and show e.g. impedance characteristics that depend on for example stretch $[4,6]$. Printed electronics technology has emerged as a new attractive tool in producing smartware [7,8]. This technology has the potential to provide smartware electrodes with improved characteristics.

(c) 2013 Rattfält et al.; licensee BioMed Central Ltd. This is an Open Access article distributed under the terms of the Creative Commons Attribution License (http://creativecommons.org/licenses/by/2.0), which permits unrestricted use, distribution, and reproduction in any medium, provided the original work is properly cited. 
The recorded ECG signal consist, besides of the bioelectric activity of the heart, also of contributions from several other sources such as electrode potential drift, liquid junction potentials over the electrolyte and the skin, myoelectric signals and capacitive coupled interferences to the mains [9-11]. If not careful actions are taken to minimize these disturbances, they might seriously distort the ECG. Muscular noise is prevented by suitable location of the electrodes and, if possible, asking the patient to relax. To lower the influence of the other sources, their origins have to be known to be able to reduce their contribution. There are mainly two properties that are of importance, the potential variation and the impedance $[9,12]$.

In this study, we have designed different three layer printed electrodes, using $\mathrm{Ag} /$ $\mathrm{AgCl}$ - and carbon based inks. The electrodes were tested for electrode potential stability and impedance frequency characteristics under well-defined electro-chemical conditions. Parts of the material have earlier been presented as conference abstracts $[13,14]$.

\section{Electrode potentials}

An electrolyte between the skin and the electrode is necessary to convey the ionic current in the body to the electronic current in the electrode. This electrolyte might be an added electrode gel or sweat accumulated under the electrode. The electrolyte and the electrode hence form a half cell which adds a potential contribution to the ECG measurement.

The half-cell potential, E, for a redox reaction can be calculated from the Nernst equation:

$$
E=E_{0}-\frac{R T}{n F} \ln \left(\frac{a_{\text {red }}}{a_{o x}}\right)
$$

where $E_{0}$ is the standard reduction potential for the redox couple, $R$ is the gas constant, $T$ the temperature, $n$ the number of electrons involved in the reaction, $F$ the Faraday constant and $a$ is the activity of the species. The possible reactions considering measurements on skin, however, are more complex due to the number of involved ions. There is also a liquid junction potential between the electrode gel and the body fluid electrolytes given by a version of the Nernst equation:

$$
E_{l j}=\left(\frac{u^{+}-u^{-}}{u^{+}+u^{-}}\right) \frac{R T}{n F} \ln \frac{C_{+}}{C_{-}}
$$

Where $u+$ and $u$ - are the mobilities of the cat- and anions, respectively, and $C_{i}$ are the electrolyte concentrations. The junction potential is low if the mobility difference between cat- and anions is small and if the mobilities are high [10].

When evaluating electrodes in the present experiments it is the open circuit potential, OCP, that is measured (with respect to the reference electrode). The OCP depends on the material of the electrode and electrolyte composition and is the sum of the halfcell potentials and the liquid junction potentials in the system. These potentials are denoted $\mathrm{E}_{1,2, \mathrm{~g}}$ in Figure 1.

Normally when recording an ECG, two or more electrodes are used. Ideally the electrodes and electrolytes are the same at all sites to minimize contributions to the differentially amplified ECG signal. However, if not the same or if the cell is disturbed by movement, a time varying potential difference can occur which is more or less difficult 


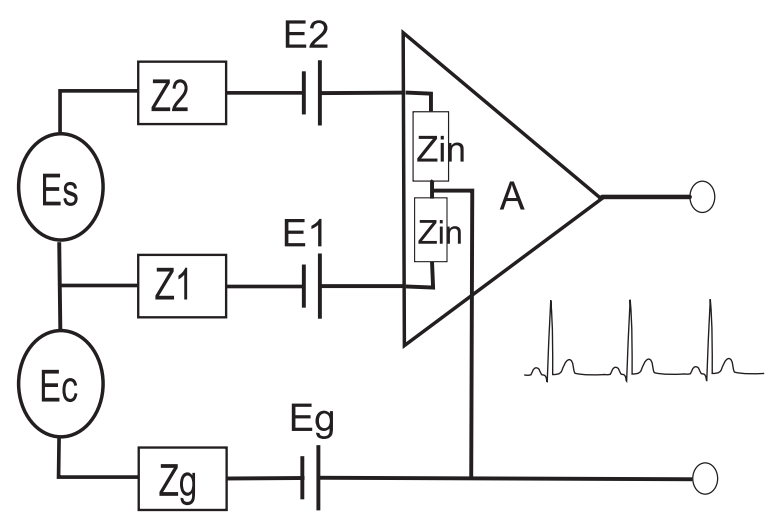

Figure 1 Simplified description of an ECG measurement setup. $E_{s}$ is the source signal, $E_{c}$ is the capacitive contribution from the mains and $Z_{1,2,9}$ are the tissue-to-electrode impedances. $Z_{\text {in }}$ is the input impedance of the amplifier and $A$ the amplification factor.

to separate from the signal from the heart. Electrode/electrolyte interfaces need therefore to be tested both for consistency and magnitude of electrode potential. By choosing stable electrode materials and suitable gel electrolytes the time fluctuation of this difference can be minimized. A commonly used clinical setup is a $\mathrm{AgCl}$-based electrode in combination with a Potassium Chloride electrolyte.

\section{Common mode disturbances}

In Figure 1 the ECG measurement setup has been modeled as an electrical circuit where $E_{s}$ is the signal from the heart and $Z_{\text {in }}$ is the input impedance of the amplifier. The impedances from the signal sources to the input of the amplifier are denoted $Z_{1,2, g}$ and are therefore total electrode impedances including both the electrode impedance itself and the skin impedance. Furthermore, the body has a capacitive and inductive coupling to the mains which depends on the presence of electrical equipment, light sources, etc. This coupling acts as a common mode ECG signal disturbance from the power line $(50 / 60 \mathrm{~Hz})$ denoted $\mathrm{E}_{\mathrm{c}}$ in Figure 1.

The amplifier's ability to suppress common mode disturbances is expressed as the Common Mode Rejection Ratio, CMRR, defined as:

$$
C M R R=10 \log _{10}\left(\frac{A}{A_{c m}}\right)^{2}
$$

where $A$ is the amplifier's differential gain and $A_{c m}$ is the common mode gain. Under the assumption that $Z_{1}$ and $Z_{2}$ are much smaller than $Z_{i n}$, the effective common mode rejection ratio is:

$$
C M R R_{\text {tot }}=1 /\left(\frac{1}{C M R R}+\frac{\Delta \mathrm{Z}}{Z_{\text {in }}}\right)
$$

Where $C M R R_{t o t}$ is the effective common mode rejection ratio, and $\Delta \mathrm{Z}=Z_{2}-Z_{1}$. This means when looking on a measurement system, the total $C M R R$ is not only depending on the CMRR for the amplifier, but also has a component where the impedances $Z_{1}$ and $Z_{2}$ are included. In order to have a satisfactory total $C M R R$ these impedances should not only be small, but also similar [9]. 
In Figure 2 the total CMRR is plotted against $\Delta \mathrm{Z}$ for input impedances of $1,10,100$ and $1000 \mathrm{M} \Omega$. The amplifier's CMRR is assumed to be $120 \mathrm{~dB}[15,16]$ and a satisfactory limit of noise suppression at line frequency is assumed to be $100 \mathrm{~dB}$ [16]. With an input impedance of $10 \mathrm{M} \Omega$ and with the assumptions above, a maximum $\Delta \mathrm{Z}$ of $10 \mathrm{k} \Omega$ is obtained. Assuming that the impedance between two sites differs maximally by $20 \%$ the highest total impedance magnitude is $50 \mathrm{k} \Omega$. Accordingly, if the input impedance is $100 \mathrm{M} \Omega$, the allowed total impedance is $500 \mathrm{k} \Omega$.

The total skin-electrode impedances in Figure 1 are the impedances from the inside of the body to the input of the amplifier. It can be further decomposed in electrical models for the tissue, skin, electrolyte, electrode and their interfaces, respectively. Included in this setup are also the printed conduction lines. Detailed models can be found in [12,17-19]. Its importance, however, for this study is the proportions between the impedance depending on the outer layer of epidermis; the cornea stratum/electrolyte (here denoted skin impedance) and the impedance of the electrode/electrolyte and the conduction line (here denoted electrode impedance). Normally the skin impedance is much larger than the electrode impedance. However, if the contribution of electrode impedance is large, it will influence $Z_{1}, Z_{2}$ and hence decrease the $C M R R$.

\section{Methods}

\section{Screen printed electrodes}

The electrodes were screen printed on a Polyethylene terephthalate (PET) foil substrate (Polyfoil Bias, 125 Mic). A flat screen printer TIC SCF 550 was used. A first layer of conductive ink was applied as a conduction line. It was either a $20 \mathrm{~mm}$ wide carbon based ink (C7102 from Dupont with 10\% Dupont 3610 thinner) or a $0.5 \mathrm{~mm}$ wide Ag based ink (Ag5000, Dupont), see Figure 3. Curing of carbon and Ag was done with a belt oven for 4 minutes at $140^{\circ} \mathrm{C}$. A second layer consisted of a $\mathrm{Ag} / \mathrm{AgCl}$ ink (Creative Materials, 113-09) circle which served as the electrode area (with a diameter of $14 \mathrm{~mm}$ ), curing of this layer was done the same way as for carbon and Ag layers. A third layer consisting of insulating lacquer (SericolUvivid Screen CN-622 Tactile Varnish) was applied resulting in an effective electrode diameter of $10 \mathrm{~mm}$, curing of the

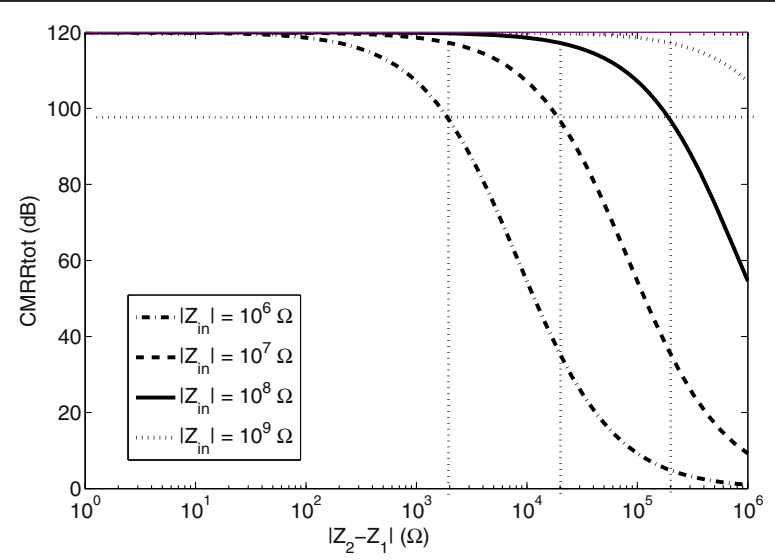

Figure 2 The effective CMRR as a function of setup parameters. The CMRR as a function of the total impedance difference between the two electrodes and input impedance in the amplifier. 

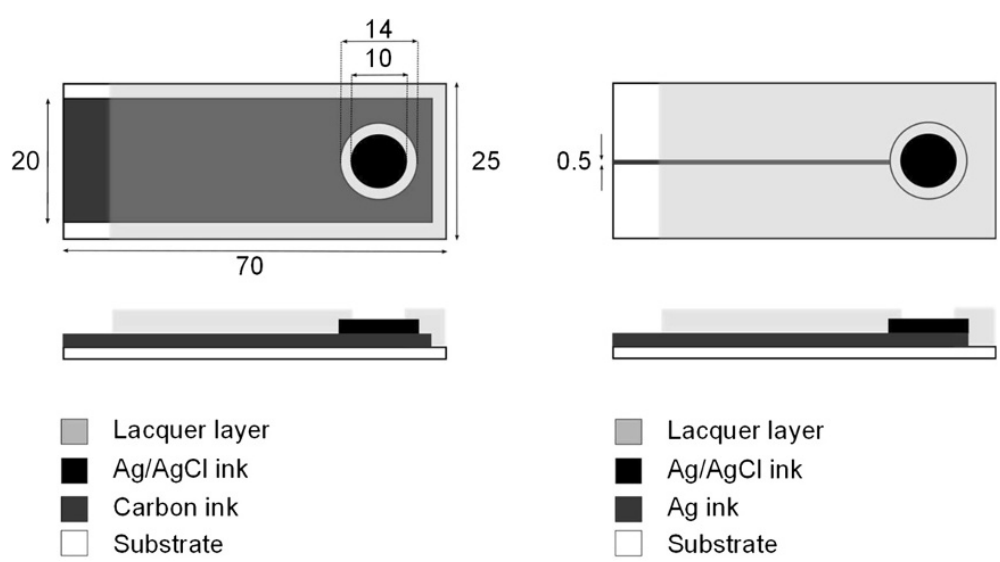

Lacquer layer

$\mathrm{Ag} / \mathrm{AgCl}$ ink

Ag ink

Substrate

Figure $\mathbf{3}$ Schematic drawing of the printed electrodes. On the left side is the Carbon conductor setup and on the right $\mathrm{Ag}$ conductor setup. All measures are in $\mathrm{mm}$.

lacquer layer was done with an Aktiprint UV dryer. In order to investigate the importance of layer thickness, a second layer of $\mathrm{Ag} / \mathrm{AgCl}$ and lacquer were reprinted in a number of the samples. Each type of electrode was printed simultaneously. The different specimens are summarized in Table 1. For comparison, measurements were also made on commercially available skin electrodes, denoted as 'commercial electrodes' (Suction Electrode KISS, GE Healthcare, $20 \mathrm{~mm}$ in diameter).

\section{Measurement setup}

The open circuit potential, OCP, and impedance for the electrodes were evaluated in an electrochemical cell consisting of physiological saline solution $(0.9 \% \mathrm{NaCl})$. The electrodes were mounted on a rigid fixture and submerged in the electrolyte. A potentiostat, Autolab PGSTAT30 (MetrohmAutolab, Utrecht) was used for the measurements along with a $\mathrm{Ag} / \mathrm{AgCl}$ reference electrode and a palladium auxiliary electrode. The open circuit potential was measured with one minute intervals during 30 minutes.

Impedance measurements were performed in the range $0.05 \mathrm{~Hz}$ to $2 \mathrm{KHz}(50 \mathrm{sam}$ ples, logarithmically distributed) with a root mean square amplitude of $10 \mathrm{mV}$ at the open circuit potential.

Table 1 Tested electrode configurations

\begin{tabular}{lllll}
\hline Denotation & Conduction line material & Layers of $\mathbf{A g} / \mathbf{A g C l}$ & Layers of lacquer & No of samples \\
\hline $\mathrm{A}_{\mathrm{Ag}}$ & $\mathrm{Ag}$ & 1 & 1 & 8 \\
$\mathrm{~A}_{\mathrm{C}}$ & $\mathrm{C}$ & 1 & 1 & 7 \\
$\mathrm{~B}_{\mathrm{Ag}}$ & $\mathrm{Ag}$ & 1 & 2 & 8 \\
$\mathrm{~B}_{\mathrm{C}}$ & $\mathrm{C}$ & 1 & 2 & 8 \\
$\mathrm{C}_{\mathrm{Ag}}$ & $\mathrm{Ag}$ & 2 & 1 & 8 \\
$\mathrm{D}_{\mathrm{Ag}}$ & $\mathrm{Ag}$ & 2 & 2 & 6 \\
Commercial & - & - & - & 4 \\
\hline
\end{tabular}




\section{Data processing}

For the electrode potential measurements, the mean drift/time, $\bar{E}_{i}$, was calculated for each electrode type, $X=\mathrm{A}_{\mathrm{Ag}}, \mathrm{A}_{\mathrm{C}}, \ldots$ as the mean absolute difference between two consecutive samples:

$$
\begin{aligned}
& \bar{E}_{X, i}=\frac{\sum_{t}\left|E_{X, i}(t)-E_{X, i}(t+1)\right|}{29}, t=1 \ldots 29 \\
& \bar{E}_{X}=\frac{\sum_{i} E_{X, i}}{n}, i=1 \ldots n
\end{aligned}
$$

Where $i$ denotes the specimen and $n$ the number of specimens of electrode type $X$. Since a few outliers were present in the dataset, the medians were chosen to present each electrode type in the electrode impedance plots. Impedance values at 1, 15, 50 and $2000 \mathrm{~Hz}$ (mean, confidence interval) were used for evaluating the impedance properties.

\section{Results}

\section{Electrode potential}

In Figure 4 the mean electrode potential is displayed for the six electrode configurations and the commercial ones. As can be seen, it varies between 53 and $59 \mathrm{mV}$. The electrode potential within the same electrode type is consistent both over time and between specimens. The largest difference between samples in one batch was for the $B_{C}$ electrode with a maximum difference of $5 \mathrm{mV}$. For the other electrode types the corresponding values were approximately $2-3 \mathrm{mV}$. The standard deviation between specimens of the same type at a given time was 0.5 to $0.8 \mathrm{mV}$, electrode $\mathrm{B}_{\mathrm{C}}$ having a slightly higher value of $2 \mathrm{mV}$ (commercial electrode $0.3 \mathrm{mV}$ ). The decrease from start to end is lower than $3 \mathrm{mV}$ for all individual electrodes. The mean potential drift is in the range

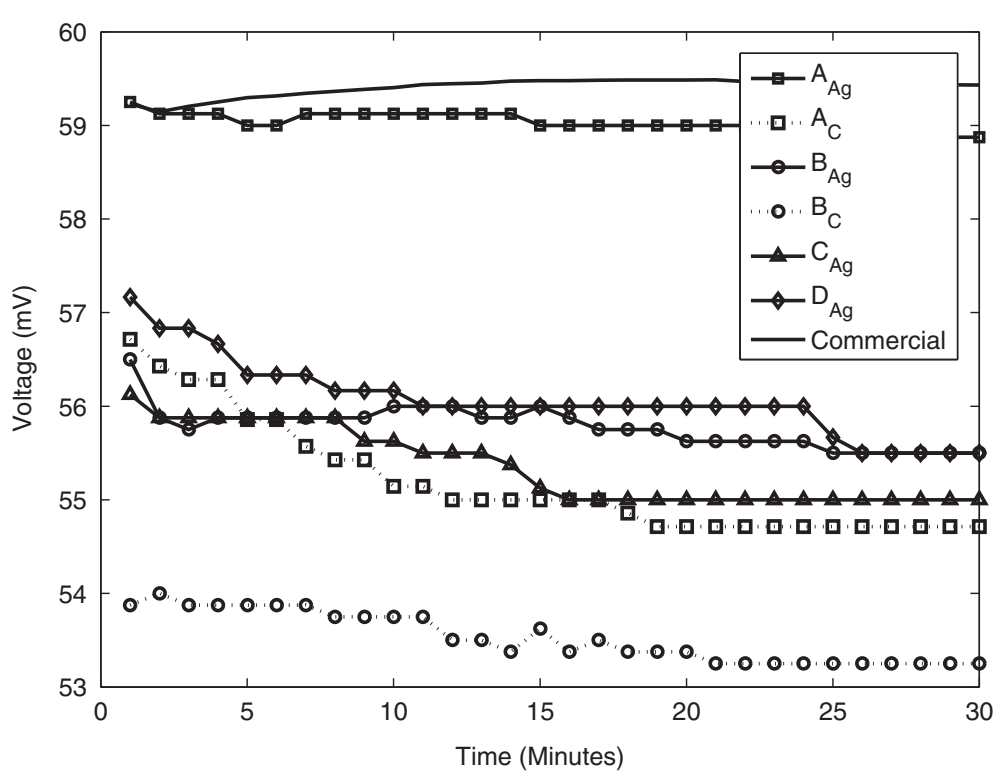

Figure 4 Mean electrode potential for each electrode. The commercial electrode has the highest potential followed by $A_{\text {Ag. }}$. 
of $0.03 \mathrm{mV} / \mathrm{min}\left(\mathrm{A}_{\mathrm{Ag}}\right)$ to $0.08 \mathrm{mV} / \mathrm{min}\left(\mathrm{B}_{\mathrm{C}}\right)$. Corresponding value for the commercial electrode is $0.02 \mathrm{mV} / \mathrm{min}$.

\section{Electrode impedance}

The median absolute values of the impedances at different frequencies are shown in Figure 5. It can be seen that at $2 \mathrm{kHz}$ the Carbon conductor electrodes have a higher resistance than the Ag-based conductor lines. For the higher frequencies, the electrodes with $\mathrm{Ag}$ conduction lines behave similarly, but with decreasing frequency, electrode type $\mathrm{A}_{\mathrm{Ag}}$ has much higher impedance.

In Figure 6 the measurement results are represented in an impedance plot. It can be seen that the reactance is capacitive but that the dominant part of the impedance is resistive.

In Table 2, the mean and 95\% confidence intervals of the impedances are specified for the different electrode types for frequencies corresponding approximately to the heart rate, QRS-complex, line frequency and maximum acquisition frequency. For noise suppression, especially the $50 \mathrm{~Hz}$ frequency is of interest. The confidence intervals are larger for low frequencies since they are more prone to be influenced by background noise. The maximal impedance at $50 \mathrm{~Hz}$ is of magnitude $1 \mathrm{k} \Omega$.

\section{Discussion}

In this study, screen printed electrodes made of conductive ink have been tested for electrode potential stability and electrode impedances.

Electrode potential drift can cause a disturbance in the measured signal which is much larger than the ECG amplitude (approx. $1 \mathrm{mV}$ ). In order to estimate the possible effect the drift might have on the measured signal, consider the relatively small P-wave of the ECG. Assuming an amplitude of $0.3 \mathrm{mV}$ and a duration about $120 \mathrm{~ms}$ [11] gives a slope of $2.5 \mathrm{mV} / \mathrm{s}$. Scaling the electrode potential drift correspondingly, its maximum

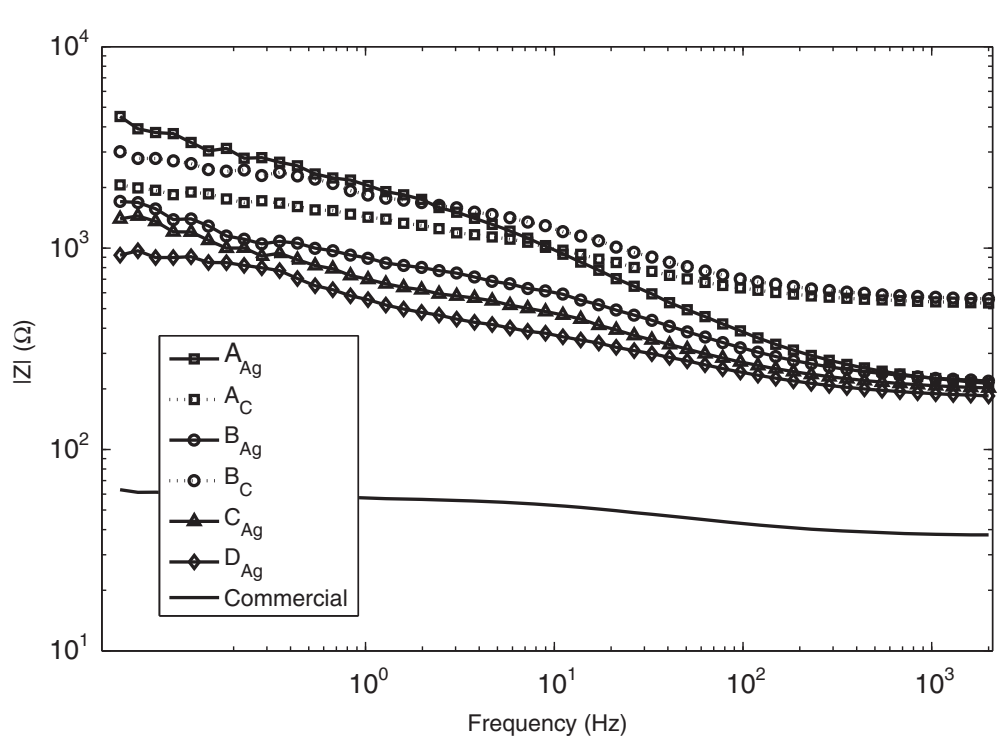

Figure 5 Absolute value of the impedance for each electrode type. Median values are used. 


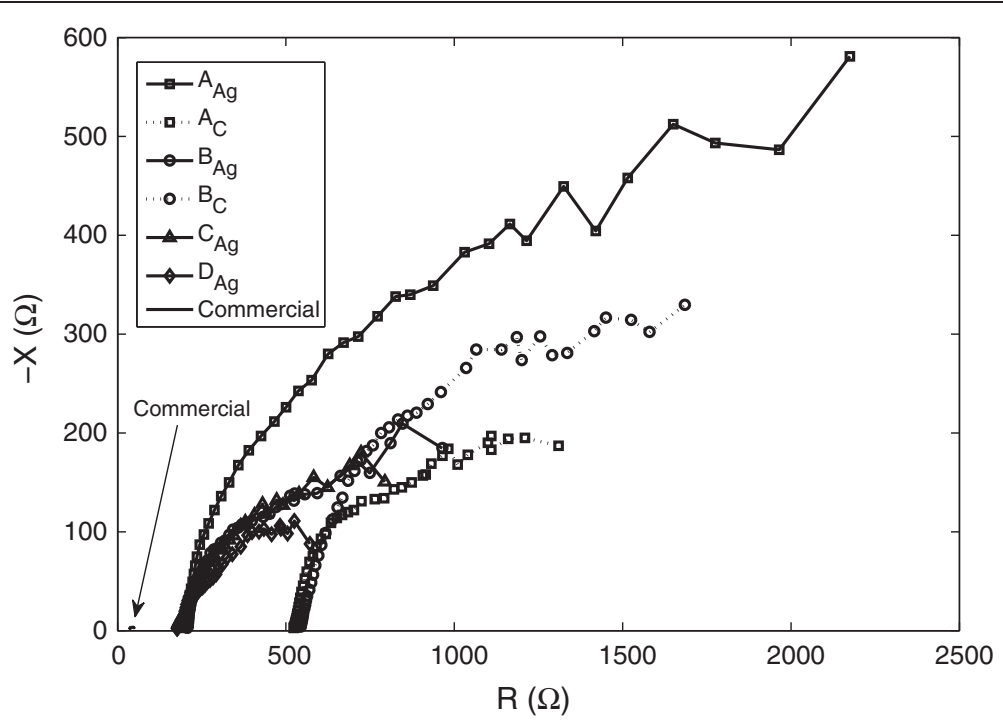

Figure 6 Impedance plot of all electrode types. Median values are used.

slope was $0.08 \mathrm{mV} / \mathrm{min}$ corresponding to $0.0013 \mathrm{mV} / \mathrm{s}$. There is a factor $10^{3}$ between the slopes which seems to be sufficient for the drift not to inflict on the ECG signal. The obtained results therefore indicate that the stability is adequate for the different electrode configurations. The potentials were also very consistent within each electrode type both regarding over time and between specimens. The printed electrodes in this sense performed comparable with the commercially available electrodes.

The magnitude of the electrolyte-electrode impedance at $50 \mathrm{~Hz}$ is an important parameter when it comes to noise suppression of artifacts induced by the mains. Here, two factors are of importance, the ratio between the skin impedance and the electrode impedance and the sum of these in comparison to the total input impedance of the amplifier. With the assumptions made in the introduction, the maximum allowed impedance difference between the two electrode sites should be $50 \mathrm{k} \Omega$. The maximal mean value of electrode impedance measured at $50 \mathrm{~Hz}$ was $1 \mathrm{k} \Omega\left(\mathrm{B}_{\mathrm{C}}\right)$ and hence is a factor 50 less than the allowed limits. It is potentially valid for only $2 \%$ of the impedance difference and should hence not be considered as a limiting factor of the entire system.

High frequency $(2 \mathrm{kHz})$ measurements show that the mean Silver conduction line electrodes have an impedance of approximately 200-250 $\Omega$ while the Carbon conduction line electrodes have corresponding value of $570-580 \Omega$. We believe that this discrepancy $(320-380 \Omega)$ is due to the difference of conductance in the conduction lines. While looking at the total measurement system, however, also the conduction lines will be added to the impedance which is coupled to the amplifier and is hence not negligible.

In this experimental setup, the skin-electrode interface has not been included. Extensive work in this area has been performed elsewhere for living tissue [20] and tissue models $[17,21]$ experiments. For the aim of this study it is sufficient to acknowledge that there can be large differences in skin impedances. For example by using regular tape to strip the skin, the impedance was reduced from $200 \mathrm{k} \Omega$ to $1 \mathrm{k} \Omega$ at $1 \mathrm{~Hz}$ after 9 repetitions [20]. For the application in mind, the electrodes should be used on 
Table 2 Impedances at some frequencies for the electrodes

\begin{tabular}{lllll}
\hline Electrode & $|\mathbf{Z}|$ at $\mathbf{1 ~ H z}$ & $|\mathbf{Z}|$ at $\mathbf{1 5} \mathbf{~ H z}$ & $|\mathbf{Z}|$ at $\mathbf{5 0 ~} \mathbf{~ H z}$ & $|\mathbf{Z}|$ at $\mathbf{2 0 0 0 ~ \mathbf { ~ z }}$ \\
\hline $\mathrm{A}_{\mathrm{Ag}}$ & $4200(2200-6100)$ & $1600(1100-2200)$ & $820(600-1000)$ & $240(210-260)$ \\
$\mathrm{A}_{\mathrm{C}}$ & $2200(1200-3200)$ & $1200(1000-1300)$ & $820(800-850)$ & $570(520-620)$ \\
$\mathrm{B}_{\mathrm{Ag}}$ & $1880(860-2800)$ & $880(760-1000)$ & $560(470-660)$ & $260(210-310)$ \\
$\mathrm{B}_{\mathrm{C}}$ & $3400(1900-5000)$ & $1600(1400-1700)$ & $1000(900-1100)$ & $580(530-630)$ \\
$\mathrm{C}_{\mathrm{Ag}}$ & $1300(600-2100)$ & $660(490-830)$ & $440(350-520)$ & $230(190-270)$ \\
$\mathrm{D}_{\mathrm{Ag}}$ & $750(530-980)$ & $440(340-550)$ & $340(260-420)$ & $200(170-230)$ \\
Commercial & $57(47-68)$ & $52(43-60)$ & $46(38-53)$ & $38(32-43)$ \\
\hline
\end{tabular}

The values are the mean and the $95 \%$ confidence interval (in brackets).

unprepared skin. However, differences in skin impedance can be large depending on the humidity and local properties of the skin. For example, the thickness of the stratum cornea varies with for example gender, age, location and humidity [22]. The skin impedance also differs much depending on frequency. Rosell et al. [23] for example, stated that the skin impedance varies from around $200 \mathrm{k} \Omega$ at $1 \mathrm{~Hz}$ to $200 \Omega$ at $1 \mathrm{MHz}$. A commonly used value for impedance for unprepared skin without gel is in the $100 \mathrm{k} \Omega$ range $[2,19,24]$. This would imply that the input impedance of the amplifier rather should be in the $100 \mathrm{M} \Omega$ range to provide sufficiently CMRR for the entire system. The impedance contribution from the electrodes themselves is, however, small.

There is a standard for disposable ECG electrodes published by the Association for the Advancement of Medical Instrument (ANSI/AAMI EC12:2000). As described by $\mathrm{Xu}$ et al. [21] it states that between two electrodes connected gel-to-gel, the maximal allowed impedance is $2 \mathrm{k} \Omega$ at $10 \mathrm{~Hz}$ (with a current less than 100 microA). Furthermore, the DC offset after one minute of stabilization is to be less than $100 \mathrm{mV}$ using the same setup. The standard is only valid for pre-gelled disposable ECG electrodes. The tested electrodes here are without gel or paste and hence cannot be compared according to the standard. Instead the measurements were performed in a controlled electro-chemical environment.

In order to improve the systems' CMRR, the amplifiers' characteristics can be improved. A general background on differential amplifiers' CMRR is given in [25]. Implementations with high input impedance are described in [24] and a solution with pre-amplified electrodes is given in [26].

By using a smooth plastic film in the electrodes, the intention was to decrease the influence of the substrate and increase the impact of the print itself in the measurements. When using textiles, the properties of the electrodes are not only defined by the ink but also vary quite drastically due to the combination of textile and printing method. Two common modalities of measuring electrical properties of prints are sheet resistance and time domain reflectometry. Such investigations have been performed on prints on fabric by $[8,27,28]$ (sheet resistance) and $[28,29]$ (time domain reflectometry). However, in the application of electrodes, the print is in contact with an electrolyte which adds a frequency dependency. The methodology used in this study therefore includes submerged electrodes.

For the final application of having printed electrodes included in garments, several other factors need to be addressed; the print could be made on textiles and conduction lines should be integrated in the garment. Furthermore, the garment might need to be 
washable. Kazani et al. [8] have used textile substrates for conductive ink screen printing and investigated its electrical properties before and after washing the fabric. It was concluded that some of the inks and substrates together with a coating still remained highly conductible even after 20 washing cycles.

\section{Conclusion}

The conclusion that can be drawn from the present experiments is that this particular ink, the $\mathrm{Ag} / \mathrm{AgCl}$, has good properties regarding electrode stability when printed on a plastic foil substrate. All electrode configurations show reasonable electrode impedances which, included in an appropriate measurement setup with high input impedance amplifiers, should not be a limiting factor. Future studies with prints on textiles and measurements on skin are, however, necessary in order to decide its applicability in tomorrow's sensor technology.

\section{Competing interests}

The authors certify that they have no competing interests.

\section{Author's contributions}

LR has been involved in the study design, made the data acquisitions and made the main part of the drafting of the manuscript. FB has substantially contributed with the methodology concerning electro-chemical measurements. DN, XW and PN have contributed in the design and conception of the printed electrodes. PA made the overall study design and contributed to the manuscript. All authors have revised the manuscript and have approved the final manuscript.

\section{Acknowledgements}

This work was supported by the funds of VINNOVA - Sweden's Innovation Agency, Linköping Initiative for Life Science Technologies (LIST) and NovaMedTech.

\section{Author details}

${ }^{1}$ Department of Biomedical Engineering, Linköping University, SE-581 83, Linköping, Sweden. ${ }^{2}$ Department of Materials Chemistry, Box 538SE-751 21, Uppsala, Sweden. ${ }^{3}$ Acreo AB, Sandgatan 31, SE-602 21, Norrköping, Sweden.

Received: 16 April 2013 Accepted: 30 June 2013

Published: 5 July 2013

References

1. Engin M, Demirel A, Engin E, Fedakar M: Recent developments and trends in biomedical sensors. Meas. 2005, 37:173-188.

2. Catrysse M, Puers R, Hertleer C, Van Langenhove L, van Egmond H, Matthys D: Towards the integration of textile sensors in a wireless monitoring suit. Sens. Actuators A-Phys 2004, 114:302-311.

3. Axisa F, Schmitt P, Gehin C, Delhomme G, McAdams E, Dittmar A: Flexible technologies and smart clothing for citizen medicine, home healthcare, and disease prevention. IEEE Trans Inf Technol Biomed 2005, 9:325-336.

4. Rattfalt $L$, Linden $M$, Hult P, Berglin L, Ask P: Electrical characteristics of conductive yarns and textile electrodes for medical applications. Med Biol Eng Comput 2007, 45:1251-1257.

5. Scilingo E, Gemignani A, Paradiso R, Taccini N, Ghelarducci B, De Rossi D: Performance evaluation of sensing fabrics for monitoring physiological and biomechanical variables. IEEE Trans Inf Technol Biomed 2005, 9:345-352.

6. Paradiso R, Loriga G, Taccini N: A wearable health care system based on knitted integrated sensors. IEEE Trans Inf Technol Biomed 2005, 9:337-344.

7. Kang T, Merritt C, Grant E, Pourdeyhimi B, Nagle H: Nonwoven fabric active electrodes for biopotential measurement during normal daily activity. leee Trans. Biomed. Eng. 2008, 55:188-195.

8. Kazani I, Hertleer C, De Mey G, Schwarz A, Guxho G, Van Langenhove L: Electrical Conductive Textiles Obtained by Screen Printing. Fibres \& Textiles in Eastern Europe 2012, 20:57-63.

9. Cobbold RS: Transducers for biomedical measurements: Principles and applications. New York: John Wiley and Sons; 1974.

10. Geddes LA: Electrodes and the measurement of bioelectric events. New York: John Wiley and Sons; 1972.

11. Sornmo L, Laguna P: Bioelectric Signal Processing in Cardiac and Neurological Applications. New York: Elsevier Inc:; 2005.

12. McAdams E, Jossinet J, Lackermeier A, Risacher F: Factors affecting electrode-gel-skin interface impedance in electrical impedance tomography. Med Biol Eng Comput 1996, 34:397-408.

13. Rattfalt L, Björefors F, Wang X, Nilsson D, Norberg P, Ask P: Electrical characterization of screen printed electrodes for ECG measurements[abstract]. In $11^{\text {th }}$ AUTEX conference (Association of Universities for Textiles). Mulhouse, France; 2011:871-873. 
14. Rattfalt L, Björefors F, Wang X, Nilsson D, Norberg P, Ask P: Electrical characterization of screen printed electrodes for ECG measurements. In Proceedings of the $15^{\text {th }}$ Nordic Baltic Conference in Biomedical Engineering and Medical Physics. 34th edition. Edited by Dremstrup K, Rees S, Jensen MØ. Aalborg, Denmark: IFMBE Proceedings; 2011:219-221.

15. Grimbergen C, Metting Van Rijn A, Kuiper A, Linnenbank A, Peper A, Morucci J, Plonsey R, Coatrieux J, Laxminarayan S: Instrumentation for the recording and digital processing of multichannel ECG data. In Proceedings of the Annual International Conference of the leee Engineering in Medicine and Biology Society, Vol 14, Pts 1-7. 14th edition. 1992:726-727.

16. Nagel HJ: Biopotential Amplifiers. In the Biomedical Engineering Handbook. 2nd edition. Edited by Bronzino JD. CRC Press; 2000

17. Beckmann L, Neuhaus C, Medrano G, Jungbecker N, Walter M, Gries T, Leonhardt S: Characterization of textile electrodes and conductors using standardized measurement setups. Physiol Meas 2010, 31:233-247.

18. Gatzke RD: the Electrode: A Measurement Systems Viewpoint. In Biomedical Electrode Technology Theory and Practice. Edited by Miller HA. Harrison DC: Academic Press Inc; 1974.

19. Neuman MR: Biopotential Electrodes. In Medical Instrumentation Application and design. Edited by Webster JG. Boca Raton: John Wiley and Sons; 2010.

20. Yamamoto T, Yamamoto Y: Electrical properties of the epidermal stratum cormeum. Med Biol Eng 1976, 14(2):151-153.

21. Xu PJ, Zhang H, Tao XM: Textile-structured electrodes for electrocardiogram. Textile Progress 2008, 40:183-213.

22. Zhen $Y$, Suetake $T$, Tagami H: Number of cell layers of the stratum corneum in normal skin - relationship to the anatomical location on the body, age, sex and physical parameters. Arch Dermatol Res 1999, 291:555-559.

23. Rosell J, Colominas J, Riu P, Pallasareny R, Webster J: Skin Impedance from $1 \mathrm{~Hz}$ to $1 \mathrm{MHz}$. leee Trans. Biomed. Eng. 1988, 35:649-651.

24. Burke M, Gleeson D: A micropower dry-electrode ECG preamplifier. leee Trans. Biomed. Eng. 2000, 47:155-162.

25. Pallasareny R, Webster J: Common-mode rejection ratio in differential-amplifiers. leee Trans. Instrum. Meas. 1991, 40:669-676.

26. Degen $\mathrm{T}$, Jackel $\mathrm{H}$ : Enhancing interference rejection of preamplified electrodes by automated gain adaption. leee Trans. Biomed. Eng. 2004, 51:2031-2039.

27. Merilampi S, Laine-Ma T, Ruuskanen P: The characterization of electrically conductive silver ink patterns on flexible substrates. Microelectron. Reliab. 2009, 49:782-790.

28. Kim Y, Kim H, Yoo H: Electrical Characterization of Screen-Printed Circuits on the Fabric. leee Trans. Advanced Packaging 2010, 33:196-205.

29. Karaguzel B, Merritt C, Kang T, Wilson J, Nagle H, Grant E, Pourdeyhimi B: Utility of nonwovens in the production of integrated electrical circuits via printing conductive inks. Journal of the Textile Institute 2008, 99:37-45.

doi:10.1186/1475-925X-12-64

Cite this article as: Rattfält et al:: Properties of screen printed electrocardiography smartware electrodes investigated in an electro-chemical cell. BioMedical Engineering OnLine 2013 12:64.

\section{Submit your next manuscript to BioMed Central and take full advantage of:}

- Convenient online submission

- Thorough peer review

- No space constraints or color figure charges

- Immediate publication on acceptance

- Inclusion in PubMed, CAS, Scopus and Google Scholar

- Research which is freely available for redistribution 